\title{
Nonoperative treatment versus volar locking plate fixation for elderly patients with distal radial fracture: a systematic review and meta-analysis
}

Qiang $\mathrm{Li}^{1 \dagger}$, Chao Ke ${ }^{2 \dagger}$, Shuang Han², Xin Xu², Yu-Xuan Cong ${ }^{2}$, Kun Shang ${ }^{2}$, Ji-Dong Liang ${ }^{1^{*}}$ and Bin-Fei Zhang ${ }^{2^{*}}$ (D)

\begin{abstract}
Background: This systematic review and meta-analysis assessed the role of nonoperative treatment and volar locking plate (VLP) fixation in elderly patients with distal radial fracture.

Methods: The systematic literature review identified randomized controlled trials (RCTs) and observational studies using VLP and nonoperative treatment for distal radial fractures in the elderly. Two investigators independently extracted data and evaluated the quality of the studies. A meta-analysis was performed using RevMan version 5.3.

Results: The five RCTs and six observational studies included 585 and 604 patients in the VLP and nonoperation groups, respectively. The quality of these 11 studies was moderate. Compared to nonoperation treatment, VLP did not improve the disabilities of the arm, shoulder and hand (DASH) score (weighted mean difference [WMD] $=$ $-1.67 ; 95 \%$ confidence interval $[\mathrm{Cl}],-3.58-0.24 ; P=0.09$ ), decrease complications (odds ratio $=1.05 ; 95 \% \mathrm{Cl}, 0.51-$ 2.19; $P=0.89$ ), or improve range of motion in flexion, extension, pronation, supination, and radial deviation. The VLP group had better grip strength $(\mathrm{WMD}=10.52 ; 95 \% \mathrm{Cl}, 6.19-14.86 ; P<0.0001)$ and radiographic assessment than the nonoperation group.

Conclusions: Although insufficient, the study evidence shows that VLP does not improve DASH scores, complications, or range of motion, but it might provide better grip strength and radiographic assessment than nonoperation treatment.
\end{abstract}

Keywords: Volar locking plate, Nonoperation, Distal radial fractures, Systematic review, Meta-analysis

\footnotetext{
*Correspondence: jd1689@163.com; zhangbf07@gmail.com

${ }^{\dagger}$ Qiang Li and Chao Ke contributed equally to this work.

'Department of Hand Surgery, Honghui Hospital, Xi'an Jiaotong University,

No. 555 Youyi East Road, Beilin District, Xi'an 710054, Shaanxi Province,

People's Republic of China

${ }^{2}$ Department of Orthopedic Trauma, Honghui Hospital, Xi'an Jiaotong University, No. 555 Youyi East Road, Beilin District, Xi'an 710054, Shaanxi

Province, People's Republic of China
}

(c) The Author(s). 2020 Open Access This article is licensed under a Creative Commons Attribution 4.0 International License, which permits use, sharing, adaptation, distribution and reproduction in any medium or format, as long as you give appropriate credit to the original author(s) and the source, provide a link to the Creative Commons licence, and indicate if changes were made. The images or other third party material in this article are included in the article's Creative Commons licence, unless indicated otherwise in a credit line to the material. If material is not included in the article's Creative Commons licence and your intended use is not permitted by statutory regulation or exceeds the permitted use, you will need to obtain permission directly from the copyright holder. To view a copy of this licence, visit http://creativecommons.org/licenses/by/4.0/ The Creative Commons Public Domain Dedication waiver (http://creativecommons.org/publicdomain/zero/1.0/) applies to the data made available in this article, unless otherwise stated in a credit line to the data. 


\section{Introduction}

Distal radial fractures are the most common fractures encountered in health care [1], accounting for about $17.5 \%$ of all fractures in 2000, especially among elderly people. Generally, the initial treatment is closed reduction and fixation with casting. However, if a good reduction cannot be achieved in the first trial or sustained in later trials, a surgical option can be considered to obtain better reduction and acceptable radiological parameters. Considering the increasing life expectancy of the elderly population, the appropriate treatment of these fractures is of growing importance.

Stable fractures can be treated with closed reduction and cast immobilization, with satisfactory outcomes in the early stage [2]. For unstable fractures, closed reduction cannot be maintained with external immobilization and additional fixation is suggested [3]. Since locking plate fixation (VLP) introduction, there has been a tendency to manage distal radial fracture in elderly people with VLP [4] and the rate of operative treatment in the elderly has increased gradually over the decades [5]. However, until recently, surgical treatment with a volar locking plate for unstable fractures among the elderly population has not been proven to be superior to nonoperative treatment [6-8]. Martinez-Mendez et al. reported significantly better function for patients treated with a VLP compared to that in nonoperative treatment [9]. Arora et al. observed no differences in function, pain, and disability scores in a randomized controlled trial [6]. Some authors have suggested that elderly patients with distal radial fractures should be managed nonoperatively because fracture reduction and anatomic alignment on radiographs are not correlated with better functional outcomes in these patients [10-12], or the correlation is not clearly proven [13]. Thus, which VLP treatment or cast application is better in the treatment of distal radial fractures in elderly patients remains controversial.

Therefore, we performed a systematic review and meta-analysis to assess the role of VLP and nonoperation on distal radial fracture function to provide clinical guidance.

\section{Methods}

\section{Inclusion and exclusion criteria}

The inclusion criteria were as follows: (1) randomized controlled trials (RCTs) or prospective or retrospective controlled studies, (2) participants aged above 50 years and with distal radial fractures, (3) patients treated surgically with VLP or nonoperation treatment with casting, (4) reported outcomes including wrist function, radiographic assessment, and complications in follow-up, (5) follow-up of at least 12 months.
The exclusion criteria were case series study without comparison groups and studies not reporting on the outcomes of interest.

\section{Literature search}

We searched the MEDLINE, Embase, and Cochrane library databases using the keywords volar plate, palmar plating, operation, surgery, distal radial fracture, radius fracture, nonoperati*, conservative, plaster, and cast. The retrieval dates included the time from database creation to September 2019. There was no limitation in the process of searching.

\section{Outcome measures}

The endpoints were disabilities of the arm, shoulder, and hand (DASH) score, grip strength, complications, range of motion, and radiographic assessment. The grip strength was presented as percentages of the uninjured side. The range of motion included flexion, extension, pronation, supination, radial deviation, and ulnar deviation. The radiographic assessment included radial height, radial inclination, ulnar variance, and volar tilt. The complications include reduction loss, revision, rupture of tendons, wound infection, nerve lesion, carpal tunnel syndrome, and complex regional pain syndrome.

\section{Data extraction and quality evaluation}

We screened all titles of the retrieved articles and removed duplicates. After eliminating irrelevant articles, the summaries of the remaining articles were assessed to confirm the adequacy of the information, followed by reading the full texts. Two investigators resolved disagreements through discussion and unresolved disagreements were discussed with a third investigator. We assessed the RCTs using Jadad scoring [14] for the generation of allocation sequence, allocation concealment, blinding, withdrawals, and efficacy of randomization. The Newcastle-Ottawa scale (NOS) was used to assess the nonrandomized studies [15].

\section{Statistical methods}

Odds ratios (ORs) and weighted mean differences (WMDs) were used for effect sizes, with 95\% confidence intervals (CIs). The statistical methods included MantelHaenszel and inverse variance tests. We assessed heterogeneity with $I^{2}$ statistics. During quantitative synthesis, a fixed-effects model was employed for low heterogeneity $\left(I^{2}<50 \%, P>0.1\right)$. When heterogeneity was high $\left(I^{2}>\right.$ $50 \%, P<0.1)$, we first explored the possible sources of heterogeneity or used a random-effects model. $P<0.05$ was considered a statistically significant difference. RevMan 5.3 version (The Cochrane Collaboration, Copenhagen, Denmark) was used to perform the analyses. 


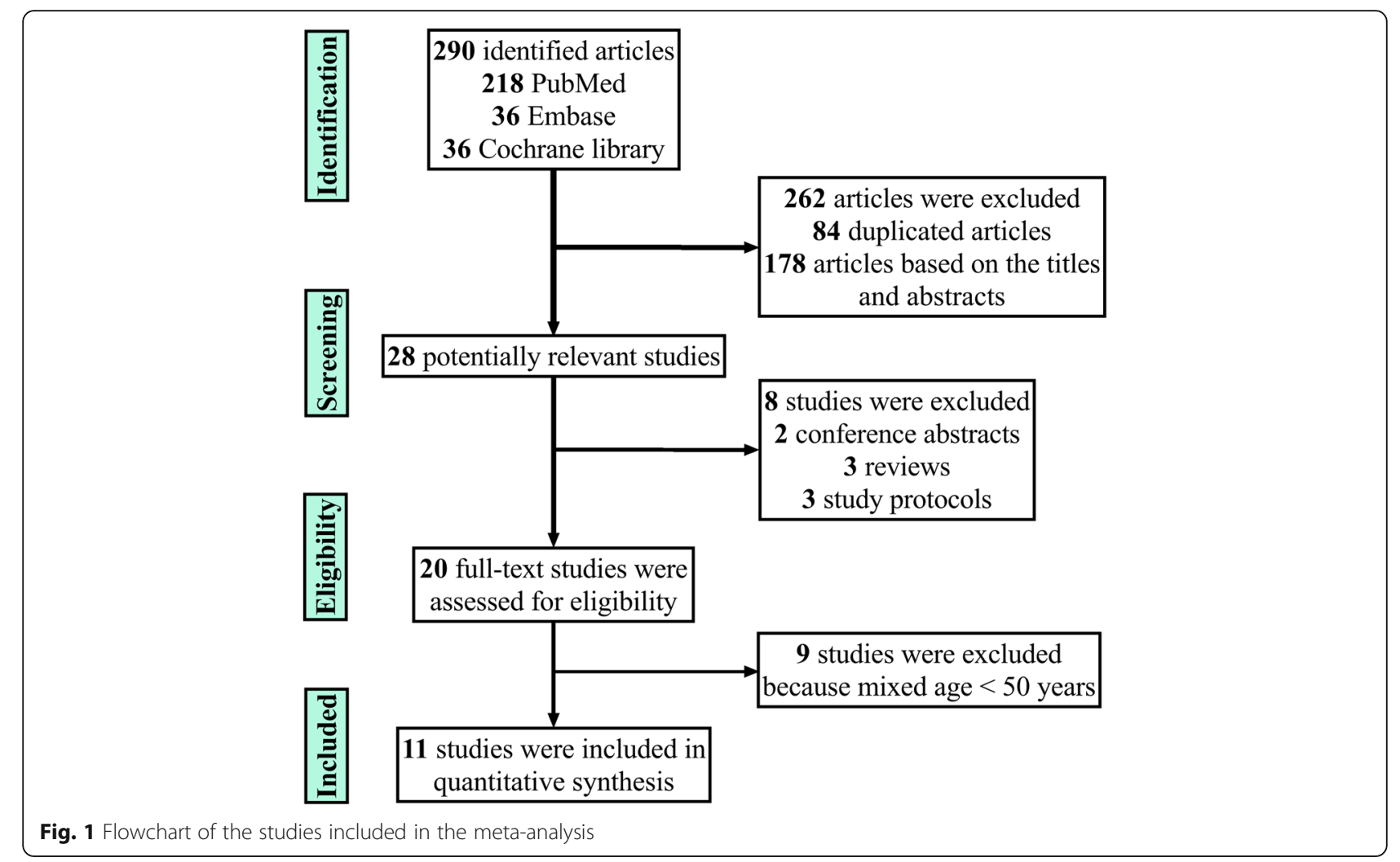

\section{Results}

\section{Including studies}

Of 290 potentially eligible articles, most were excluded due to duplicates and lack of relevance. Finally, 11 studies $[4,6,7,9,16-22]$, including five RCTs $[6,7,9,20,21]$, five retrospective studies $[4,16-18,22]$, and one prospective study [19], satisfied the inclusion criteria after screening and assessment. The studies were published from 2009 to 2019 , most within the past 5 years. Figure 1 shows the flow of studies through the trial.

\section{Characteristics and quality evaluation of the included studies}

Eleven studies with a total of 1189 patients were included. Of these, 585 were in the VLP group and 604 were in the nonoperation group. The sample sizes ranged from 67 to 258 patients. The 1005 women comprised $84.52 \%$ of all patients. The lowest age in all studies was more than 50 years and most were more than 65 years of age. The VLP was used in the operation group by ORIF. Casting and plaster splints were used in the nonoperation group. All studies evaluated wrist function and treatment complications. The follow-up times varied from 12 to 55 months, as shown in Table 1 .

The quality of the included studies was assessed according to the above-referenced criteria. Among the five RCTs, Arora 2011 [6] did not include detailed information about the generation of the randomization sequence; the remaining RCTs reported that the randomization sequence was generated by computers or random number tables. All RCTs performed allocation concealment in opaque envelopes. Arora 2011 [6] reported that the assessor of the radiographic outcomes was blinded, resulting in a low risk of bias. However, the other RCTs did not report blinding. All RCTs reported information about withdrawals and no patients were lost to follow-up. Thus, the quality of the five RCTs was moderate (Table 2). The NOS was used to assess the quality of the retrospective and prospective studies, as shown in Table 3. The total scores ranged from 4 to 7 , corresponding to moderate quality. Overall, the quality of the included studies was moderate.

\section{Primary endpoints}

\section{DASH score and grip strength}

Seven studies compared DASH scores between VLP and nonoperation groups $[6,7,16-18,20,22]$. As shown in Fig. 2, the $I^{2}$ value for heterogeneity was $57 \%(P=0.03)$. After excluding the possibility of clinical heterogeneity, a random-effects model was applied. The DASH score in the VLP group was comparable to that in the nonoperation group (WMD $=-1.67 ; 95 \% \mathrm{CI},-3.58-0.24 ; P=0.09$ ). When the aggregate results of these studies were divided into two subgroups according to the study design, the 


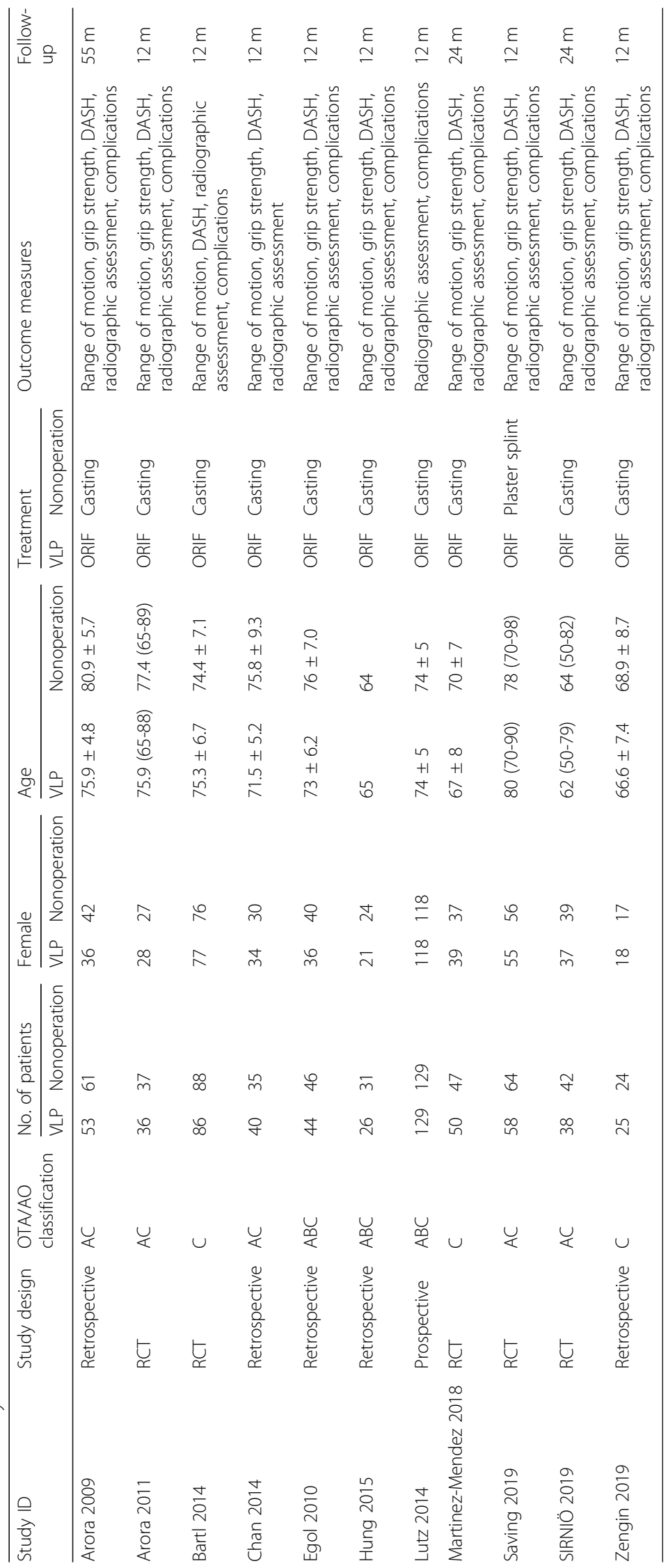


Table 2 Quality assessment of the included randomized controlled trials (RCTs)

\begin{tabular}{|c|c|c|c|c|c|}
\hline Study ID & Generation of randomization Sequence & Allocation concealment & Blinding & Withdrawals & Total score \\
\hline Arora 2011 [6] & 1 & 2 & 1 & 1 & 4 \\
\hline Bartl 2014 [7] & 2 & 2 & 0 & 1 & 5 \\
\hline Martinez-Mendez 2018 [9] & 2 & 2 & 0 & 1 & 5 \\
\hline Saving 2019 [20] & 2 & 2 & 0 & 1 & 5 \\
\hline SIRNIÖ 2019 [21] & 2 & 2 & 0 & 1 & 5 \\
\hline
\end{tabular}

results from RCTs showed a lower DASH score in the VLP group than that in the nonoperation group (WMD = -4.37 ; 95\% CI, -7.52--1.21; $P=0.007)$. There were no significant differences in the results from retrospective studies (WMD $=-0.20 ; 95 \% \mathrm{CI},-1.60-1.21 ; P=0.78)$.

Five studies evaluated grip strength $[4,9,17,20,22]$. As shown in Fig. 3, since the $I^{2}$ value for heterogeneity was $0 \%(P=0.44)$, a fixed-effects model was used. The VLP group had significantly better grip strength than that in the nonoperation group (WMD $=10.52 ; 95 \% \mathrm{CI}$, 6.19-14.86; $P<0.0001)$. The results remained stable in the sensitivity analysis that excluded individual studies.

\section{Secondary endpoints \\ Complications}

Eleven studies reported complications [4, 6, 7, 9, 16-22]. As shown in Fig. 4, the aggregate resulted in an $I^{2}$ value for heterogeneity of $79 \%(P<0.0001)$; thus, a randomeffects model was used. No significant difference in the rate of complications $(\mathrm{OR}=1.05 ; 95 \% \mathrm{CI}, 0.51-2.19 ; P=$ $0.89)$ was observed between groups. The results remained stable in a sensitivity analysis that excluded individual studies. When the aggregate results of these studies were divided into two subgroups according to the study design, the RCTs showed no significant difference in complications between the VLP and nonoperation groups $(\mathrm{OR}=$ 0.94; 95\% CI, 0.24-3.60; $P=0.92$ ). There were also no significant differences in the results of the observational studies $(\mathrm{OR}=1.47 ; 95 \% \mathrm{CI}, 0.84-2.60 ; P=0.18)$.

\section{Range of motion}

Most studies assessed the range of motion. As shown in Table 4, the aggregate results showed $I^{2}$ values for heterogeneity in flexion, pronation, supination, radial deviation, and ulnar deviation of more than 50\%; thus, the random-effects model was used. A significant difference between groups was observed only for ulnar deviation (WMD $=2.22 ; 95 \% \mathrm{CI}, 0.19-4.26 ; P=0.03$ ), in which the ulnar deviation in the VLP group was higher than that in the nonoperation group. There were no significant differences in the field of flexion, extension, pronation, supination, and radial deviation.

\section{Radiographic assessment}

Most studies performed radiographic assessment. As shown in Table 4, the aggregate results showed $I^{2}$ values for heterogeneity in radial height, radial inclination, ulnar variance, and volar tilt of more than $50 \%$; thus, the random-effects model was used. There were significant differences between the two groups in radial height (WMD $=2.44 ; 95 \% \mathrm{CI}, 1.22-3.67 ; P<0.00001$ ), radial inclination $(\mathrm{WMD}=3.81 ; 95 \% \mathrm{CI}, 2.92-4.70 ; P<$ 0.00001 ), and volar tilt (WMD $=6.39 ; 95 \% \mathrm{CI}, 0.18-$ 12.59; $P=0.04$ ). The radial height, radial inclination, and volar tilt in the VLP group were better than those in the nonoperation group. No significant differences in ulnar variance were observed (WMD $=-0.89 ; 95 \% \mathrm{CI}$, -1.92-0.13; $P=0.09$ ).

Table 3 Quality assessment of the included retrospective and prospective studies

\begin{tabular}{|c|c|c|c|c|c|c|c|}
\hline \multirow[t]{2}{*}{ Study ID } & \multicolumn{3}{|l|}{ Selection } & \multirow{2}{*}{$\begin{array}{l}\text { Comparability } \\
\text { Comparability of cohorts } \\
\text { on the basis of the design } \\
\text { or analysis }\end{array}$} & \multicolumn{2}{|l|}{ Outcome } & \multirow{2}{*}{$\begin{array}{l}\text { Total } \\
\text { score }\end{array}$} \\
\hline & $\begin{array}{l}\text { Representativeness } \\
\text { of exposed cohort }\end{array}$ & $\begin{array}{l}\text { Selection of } \\
\text { non-exposed } \\
\text { cohort }\end{array}$ & $\begin{array}{l}\text { Ascertainment } \\
\text { of exposure }\end{array}$ & & $\begin{array}{l}\text { Assessment } \\
\text { of outcome }\end{array}$ & $\begin{array}{l}\text { Adequacy of } \\
\text { follow up of } \\
\text { cohorts }\end{array}$ & \\
\hline Arora 2009 [16] & 0 & 1 & 1 & 2 & 1 & 1 & 6 \\
\hline Chan 2014 [17] & 0 & 1 & 1 & 2 & 1 & 1 & 6 \\
\hline Egol 2010 [18] & 1 & 1 & 1 & 2 & 1 & 1 & 7 \\
\hline Hung 2015 [4] & 1 & 1 & 1 & 2 & 1 & 1 & 7 \\
\hline Lutz 2014 [19] & 0 & 1 & 1 & 1 & 0 & 1 & 4 \\
\hline Zengin 2019 [22] & 0 & 1 & 1 & 2 & 1 & 1 & 6 \\
\hline
\end{tabular}




\begin{tabular}{|c|c|c|c|c|c|c|c|c|c|c|}
\hline \multirow[b]{2}{*}{ Study or Subgroup } & \multicolumn{3}{|c|}{ Volar Locking Plate } & \multicolumn{3}{|c|}{ Nonoperation } & & \multirow{2}{*}{$\begin{array}{l}\text { Mean Difference } \\
\text { IV. Random, } 95 \% \mathrm{CI}\end{array}$} & \multirow{2}{*}{\multicolumn{2}{|c|}{$\begin{array}{l}\text { Mean Difference } \\
\text { IV. Random. } 95 \% \mathrm{CI}\end{array}$}} \\
\hline & Mean & SD & Total & Mean & SD & Total & Weight & & & \\
\hline Arora 2009 & 11.1 & 4.35 & 53 & 11.6 & 4.525 & 61 & $28.8 \%$ & $-0.50[-2.13,1.13]$ & $F$ & \\
\hline Arora 2011 & 5.7 & 11.1 & 36 & 8 & 9.3 & 37 & $11.4 \%$ & $-2.30[-7.00,2.40]$ & 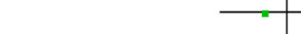 & 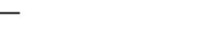 \\
\hline Bartl 2014 & 14 & 16.1 & 86 & 19 & 21.3 & 88 & $8.8 \%$ & $-5.00[-10.60,0.60]$ & & \\
\hline Chan 2014 & 6.7 & 1.9 & 40 & 6.2 & 1.9 & 35 & $34.0 \%$ & $0.50[-0.36,1.36]$ & $=$ & $=$ \\
\hline Egol 2010 & 10 & 20.3 & 44 & 12.1 & 29.6 & 46 & $3.1 \%$ & $-2.10[-12.55,8.35]$ & & \\
\hline Saving 2019 & 15.6 & 17 & 58 & 23.1 & 19.8 & 64 & $6.9 \%$ & $-7.50[-14.03,-0.97]$ & & \\
\hline Zengin 2019 & 11.7 & 8 & 25 & 17.6 & 14.2 & 24 & $7.0 \%$ & $-5.90[-12.39,0.59]$ & & \\
\hline Total $(95 \% \mathrm{Cl})$ & & & 342 & & & 355 & $100.0 \%$ & $-1.67[-3.58,0.24]$ & & \\
\hline \multicolumn{9}{|c|}{$\begin{array}{l}\text { Heterogeneity: } \text { Tau }^{2}=2.60 ; \mathrm{Chi}^{2}=14.00, \mathrm{df}=6(\mathrm{P} \\
\text { Test for overall effect: } Z=1.72(P=0.09)\end{array}$} & $\begin{array}{ccc}-20 & -10 & 0 \\
\text { Favours Volar Locking Plate }\end{array}$ & $\begin{array}{cc}10 & 20 \\
\text { Favours Nonoperation }\end{array}$ \\
\hline
\end{tabular}

\section{Publication bias}

Publication bias was assessed using complications for analysis. The symmetry shown in Fig. 5 suggested that publication bias was not likely.

\section{Discussion}

Several recent studies have reported satisfactory functional results in elderly patients despite malunion $[6,16]$. Some authors have suggested nonoperative management of elderly patients with distal radial fractures [10-12], and have demonstrated very good clinical outcomes in these patients [23]. Conversely, other authors have reported that articular reconstruction using VLP provides predictable results, especially in osteoporotic elderly patients [17]. In 2003, a Cochrane systematic review suggested that, despite the poorer radiological results, the functional outcome of nonoperative therapy did not differ from that of surgical management in patients over 60 years of age [24]. In their review of distal radius fracture in elderly patients, Ju et al. [8] reported similar functional outcomes and quality of life between operation and nonoperation. However, Handoll et al. [24] and Ju et al. [8] included external fixation, percutaneous pinning, ORIF, and scaffolding-bone graft/substitute in their operation groups; thus, the treatments varied. Studies comparing different surgical protocols $[25,26]$ concluded that ORIF with a plate might be the best surgical protocol for patients with distal radius fracture.
Contrarily, other high-quality systematic review indicates there is no clear superiority between VLP and other common fixations [27]. The patient age in these systematic reviews varied widely and included elderly and nonelderly patients. The methods of reduction and fixation fracture in patients with osteoporosis differ from those in adults. The current literature on the treatment of distal radial fractures in the elderly remains controversial. Especially, in clinical practice, how should we give the weight to radiographic results and functional results? In a recent randomized study, Caruso et al. found radiological parameters outside the range conventionally considered acceptable do not preclude a satisfactory clinical outcome [28]. Thus, there is lack of the correlation between clinical and radiographic results in the elderly, and a strategy for elderly patients is required.

Thus, the present systematic review assessed the influence of VLP and nonoperation on distal radial fracture. The main findings were (a) no significant difference in DASH scores, complications, or range of motion and (b) better grip strength and radiographic assessment in the VLP group than those in the nonoperation group.

The primary outcomes in the present study were DASH score and grip strength. The DASH is an effective tool for assessing wrist functional disability in distal radial fractures $[29,30]$. No differences in range of motion and complications were observed between the VLP and nonoperation treatment groups. Therefore, the

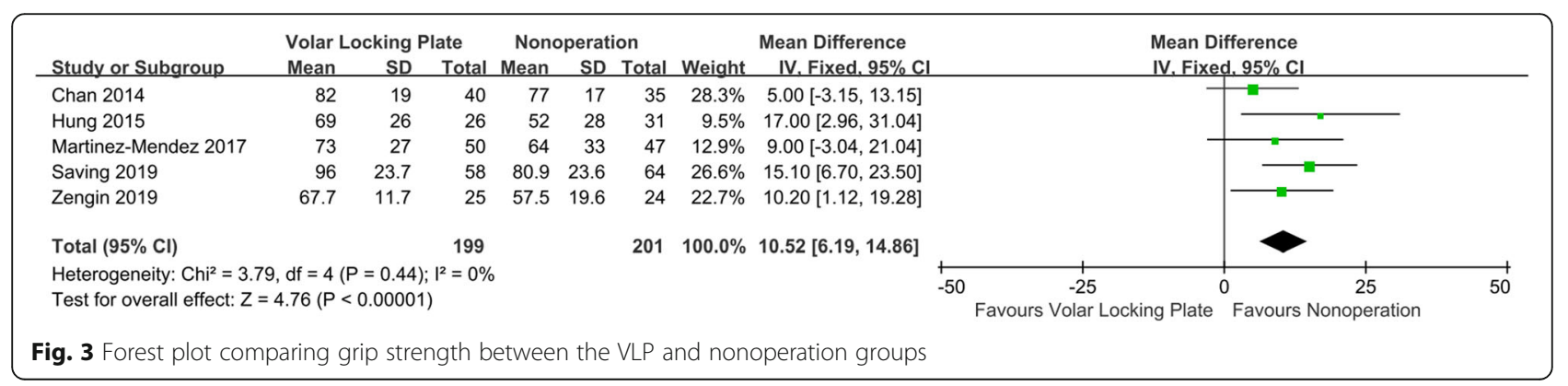




\begin{tabular}{|c|c|c|c|c|c|c|c|c|c|}
\hline \multirow[b]{2}{*}{ Study or Subgroup } & \multicolumn{2}{|c|}{ Volar Locking Plate } & \multicolumn{3}{|c|}{ Nonoperation } & \multirow{2}{*}{$\begin{array}{l}\text { Odds Ratio } \\
\text { M-H, Random, } 95 \% \mathrm{Cl}\end{array}$} & \multirow{2}{*}{\multicolumn{3}{|c|}{$\begin{array}{l}\text { Odds Ratio } \\
\text { M-H, Random, } 95 \% \mathrm{Cl}\end{array}$}} \\
\hline & Events & Total & Events & Total & Weight & & & & \\
\hline Arora 2009 & 7 & 53 & 5 & 61 & $9.7 \%$ & $1.70[0.51,5.73]$ & & $=$ & \\
\hline Arora 2011 & 13 & 36 & 5 & 37 & $9.9 \%$ & $3.62[1.13,11.57]$ & & & \\
\hline Bartl 2014 & 19 & 86 & 53 & 88 & $11.9 \%$ & $0.19[0.10,0.36]$ & & & \\
\hline Chan 2014 & 5 & 40 & 5 & 35 & $9.2 \%$ & $0.86[0.23,3.25]$ & & & \\
\hline Egol 2010 & 7 & 44 & 4 & 46 & $9.3 \%$ & $1.99[0.54,7.33]$ & & & \\
\hline Hung 2015 & 0 & 26 & 1 & 31 & $3.7 \%$ & $0.38[0.01,9.82]$ & & & \\
\hline Lutz 2014 & 50 & 129 & 27 & 129 & $12.2 \%$ & $2.39[1.38,4.16]$ & & $\longrightarrow$ & \\
\hline Martinez-Mendez 2017 & 2 & 50 & 1 & 47 & $5.4 \%$ & $1.92[0.17,21.86]$ & & . & \\
\hline Saving 2019 & 38 & 58 & 31 & 64 & $11.6 \%$ & $2.02[0.97,4.20]$ & & & \\
\hline SIRNIÖ 2019 & 3 & 38 & 8 & 42 & $8.8 \%$ & $0.36[0.09,1.49]$ & & - & \\
\hline Zengin 2019 & 3 & 25 & 6 & 24 & $8.4 \%$ & $0.41[0.09,1.87]$ & & & \\
\hline Total $(95 \% \mathrm{Cl})$ & & 585 & & 604 & $100.0 \%$ & $1.05[0.51,2.19]$ & & & \\
\hline Total events & 147 & & 146 & & & & & & \\
\hline \multirow{2}{*}{\multicolumn{6}{|c|}{$\begin{array}{l}\text { Heterogeneity: } \mathrm{Tau}^{2}=1.06 ; \mathrm{Chi}^{2}=47.63, \mathrm{df}=10(P<0.00001) ;\left.\right|^{2}=79 \% \\
\text { Test for overall effect: } Z=0.14(P=0.89)\end{array}$}} & & $0.005 \quad 0.1$ & & 200 \\
\hline & & & & & & & Favours Volar Locking Plate & Favours Nonoperation & 200 \\
\hline
\end{tabular}

functional results of the two methods do not differ significantly. The result is similar to that of another metaanalysis containing only elderly patients [8]. The grip strength of the surgical group was significantly higher than that of the nonoperation group. In terms of radiographic evaluation, VLP improved four parameters after ORIF of the distal radius fracture. However, in elderly patients with mainly functional requirements, the recovery of the appearance of the wrist and improved radiographic parameters may be less important than the function. Therefore, there was little difference in function between the two groups, but there were differences in grip strength. In elderly patients, if the expected quality of life is high or the injured wrist is on the advantage upper extremity, VLP treatment may achieve better results. If the patient is older, the expected quality of life is not high, or if the injury wrist is on the disadvantage upper extremity, conservative treatment should be considered.

The complications include reduction loss, revision, tendon rupture of, wound infection, nerve lesion, carpal tunnel syndrome, and complex regional pain syndrome. Carpal tunnel symptoms, reduction loss, and complex regional pain syndrome occurred more often in the nonoperation group [7]. Revision, tendon rupture, wound infection, and nerve lesions occurred more often in the VLP group [19].

Our meta-analysis has several limitations. First, the study included RCTs and observational studies. One study reported that observational studies may exaggerate the actual role of VLP [31]. Second, a slight statistical heterogeneity was observed among the included studies, which could have affected the results. Third, the quality of these studies was moderate. Thus, the results should

Table 4 Range of motion and radiographic assessment of retrospective and prospective studies

\begin{tabular}{|c|c|c|c|c|c|}
\hline \multirow[t]{2}{*}{ Items } & \multirow[t]{2}{*}{ Number of studies } & \multirow{2}{*}{$\begin{array}{l}\text { Mean difference } \\
{[95 \% \mathrm{Cl}]}\end{array}$} & \multirow[t]{2}{*}{$P$} & \multicolumn{2}{|c|}{ Heterogeneity } \\
\hline & & & & $P(\%)$ & $P$ \\
\hline \multicolumn{6}{|l|}{ Range of motion } \\
\hline Flexion & $7[6,7,9,16,18,20,21]$ & $-0.45[-5.14,4.24]$ & 0.85 & 87 & $<0.00001$ \\
\hline Extension & $7[6,7,9,16,18,20,21]$ & $-0.29[-1.82,1.23]$ & 0.71 & 0 & 0.42 \\
\hline Pronation & $7[6,7,9,16,18,20,21]$ & $1.03[-1.08,3.15]$ & 0.34 & 71 & 0.02 \\
\hline Supination & $7[6,7,9,16,18,20,21]$ & $1.42[-1.37,4.20]$ & 0.32 & 78 & 0.0001 \\
\hline Radial deviation & $6[6,7,16,18,20,21]$ & $-0.21[-1.37,0.95]$ & 0.72 & 26 & 0.24 \\
\hline Ulnar deviation & $6[6,7,16,18,20,21]$ & $2.22[0.19,4.26]$ & 0.03 & 62 & 0.02 \\
\hline \multicolumn{6}{|c|}{ Radiographic assessment } \\
\hline Radial height & $4[4,9,18,22]$ & $2.44[1.22,3.67]$ & $<0.00001$ & 79 & 0.003 \\
\hline Radial inclination & $11[4,6,7,9,16-22]$ & $3.81[2.92,4.70]$ & $<0.00001$ & 63 & 0.002 \\
\hline Ulnar variance & $10[4,6,7,9,16-19,21,22]$ & $-0.89[-1.92,0.13]$ & 0.09 & 94 & $<0.00001$ \\
\hline Volar tilt & $11[4,6,7,9,16-22]$ & $6.39[0.18,12.59]$ & 0.04 & 97 & $<0.00001$ \\
\hline
\end{tabular}




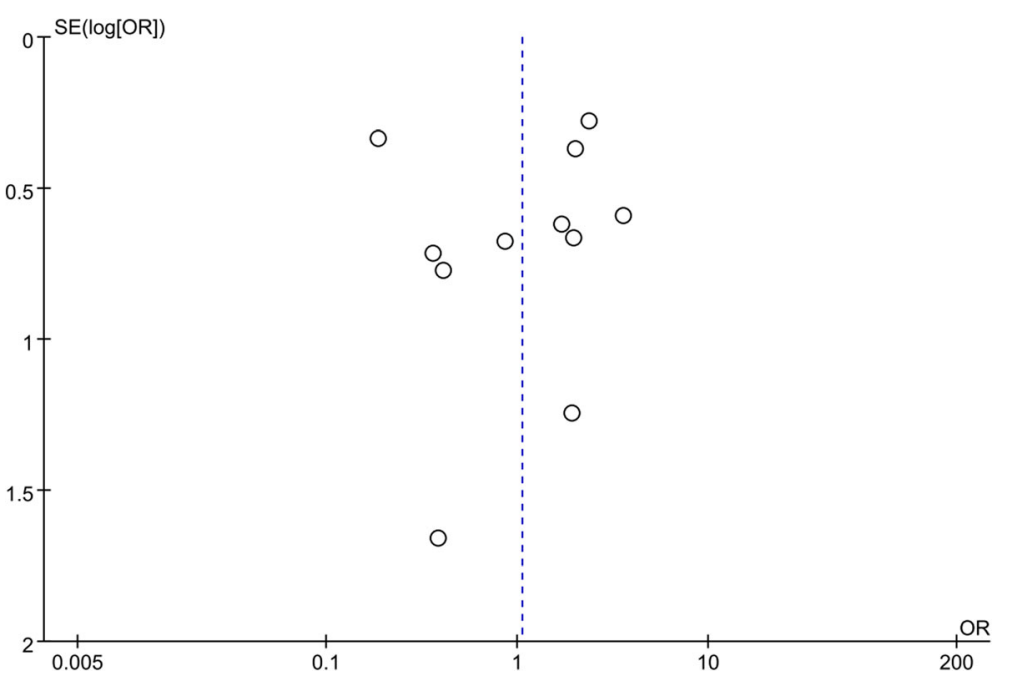

Fig. 5 Funnel plot comparing complications between the VLP and nonoperation groups. The $y$-axis represents the standard error (SE) (log [OR]), while the $x$-axis represents the odds ratio (OR). The sloped lines represent the $95 \% \mathrm{Cl}$ boundaries and the circles indicate the 11 studies

be cautiously interpreted. A large-scale study is needed to identify the role of VLP and nonoperation. Fourth, the use of arthroscopy is increasingly popular in the last years and providing a better anatomical reduction [32], but VLP group in most of studies do not report the usage of arthroscopy. In addition, the issue of the difference between articular and extra-articular fractures is never addressed. This could affect the results and could be another inherent limitation of the study.

\section{Conclusions}

Although insufficient, the evidence from this study showed that VLP might not improve the DASH score, complications, or range of motion. VLP might provide better grip strength and radiographic assessment compared to nonoperation.

\section{Abbreviations}

VLP: Volar locking plate; RCT: Randomized controlled trials; DASH: Disabilities of the arm, shoulder, and hand; WMD: Weighted mean difference;

Cl: Confidence interval; NOS: Newcastle-Ottawa scale; OR: Odds ratios

\section{Acknowledgements}

Not applicable

\section{Authors' contributions}

According to the definition given by the International Committee of Medical Journal Editors (ICMJE), the authors listed above qualify for authorship based on making one or more of the substantial contributions to the intellectual content of the following: Conceived and designed the study: BF Z, JD L. Performed the study: BF Z, S H, YX C, X X, K S, C K. Analyzed the data: BF Z, S $H$. Wrote the manuscript: $Q L$ and $C K$. The author(s) read and approved the final manuscript.
Availability of data and materials

Data sharing is not applicable to this article as no datasets were generated or analyzed during the current study

Ethics approval and consent to participate

Not applicable. The study was waived by the Ethics Committee of the Xi'an Jiaotong University.

\section{Consent for publication}

Not applicable

\section{Competing interests}

The authors declare that they have no competing interests.

Received: 29 April 2020 Accepted: 27 May 2020

Published online: 14 July 2020

\section{References}

1. Court-Brown CM, Caesar B. Epidemiology of adult fractures: a review. Injury. 2006;37(8):691-7.

2. McQueen MM, Hajducka C, Court-Brown CM. Redisplaced unstable fractures of the distal radius: a prospective randomised comparison of four methods of treatment. J Bone Joint Surg (Br). 1996;78(3):404-9.

3. McQueen MM, MacLaren A, Chalmers J. The value of remanipulating Colles' fractures. J Bone Joint Surg (Br). 1986;68(2):232-3.

4. Hung LP, Leung YF, Ip WY, Lee YL. Is locking plate fixation a better option than casting for distal radius fracture in elderly people? Hong Kong Med J. 2015;21(5):407-10

5. Huetteman HE, Shauver MJ, Malay S, Chung T, Chung KC. Variation in the treatment of distal radius fractures in the United States: 2010 to 2015. Plast Reconstr Surg. 2019;143(1):159-67.

6. Arora R, Lutz M, Deml C, Krappinger D, Haug L, Gabl M. A prospective randomized trial comparing nonoperative treatment with volar locking plate fixation for displaced and unstable distal radial fractures in patients sixty-five years of age and older. J Bone Joint Surg Am. 2011;93(23):2146-53.

7. Bartl C, Stengel D, Bruckner T, Gebhard F, Group OS. The treatment of displaced intra-articular distal radius fractures in elderly patients. Dtsch Arztebl Int. 2014;111(46):779-87.

8. Ju JH, Jin GZ, Li GX, Hu HY, Hou RX. Comparison of treatment outcomes between nonsurgical and surgical treatment of distal radius fracture in elderly: a systematic review and meta-analysis. Langenbeck's Arch Surg. 2015;400(7):767-79. 
9. Martinez-Mendez D, Lizaur-Utrilla A. de-Juan-Herrero J. Intra-articular distal radius fractures in elderly patients: a randomized prospective study of casting versus volar plating. J Hand Surg Eur Vol. 2018;43(2):142-7.

10. Young BT, Rayan GM. Outcome following nonoperative treatment of displaced distal radius fractures in low-demand patients older than 60 years. J Hand Surg [Am]. 2000;25(1):19-28.

11. Barton T, Chambers C, Bannister G. A comparison between subjective outcome score and moderate radial shortening following a fractured distal radius in patients of mean age 69 years. J Hand Surg Eur Vol. 2007;32(2): 165-9.

12. Grewal R, MacDermid JC, King GJ, Faber KJ. Open reduction internal fixation versus percutaneous pinning with external fixation of distal radius fractures: a prospective, randomized clinical trial. J Hand Surg [Am]. 2011;36(12):1899-906.

13. Blakeney WG. Stabilization and treatment of Colles' fractures in elderly patients. Clin Interv Aging. 2010;5:337-44.

14. Jadad AR, Moore RA, Carroll D, Jenkinson C, Reynolds DJM, Gavaghan DJ, et al. Assessing the quality of reports of randomized clinical trials: is blinding necessary? Control Clin Trials. 1996;17(1):1-12.

15. Stang A. Critical evaluation of the Newcastle-Ottawa scale for the assessment of the quality of nonrandomized studies in meta-analyses. Eur J Epidemiol. 2010;25(9):603-5.

16. Arora R, Gabl M, Gschwentner M, Deml C, Krappinger D, Lutz M. A comparative study of clinical and radiologic outcomes of unstable Colles type distal radius fractures in patients older than 70 years: nonoperative treatment versus volar locking plating. J Orthop Trauma. 2009;23(4):237-42.

17. Chan YH, Foo TL, Yeo CJ, Chew WY. Comparison between cast immobilization versus volar locking plate fixation of distal radius fractures in active elderly patients, the Asian perspective. Hand Surg. 2014;19(1):19-23.

18. Egol KA, Walsh M, Romo-Cardoso S, Dorsky S, Paksima N. Distal radial fractures in the elderly: operative compared with nonoperative treatment. J Bone Joint Surg Am. 2010;92(9):1851-7.

19. Lutz K, Yeoh KM, MacDermid JC, Symonette C, Grewal R. Complications associated with operative versus nonsurgical treatment of distal radius fractures in patients aged 65 years and older. J Hand Surg [Am]. 2014;39(7): 1280-6.

20. Saving J, Severin Wahlgren S, Olsson K, Enocson A, Ponzer S, Skoldenberg $\mathrm{O}$, et al. Nonoperative treatment compared with volar locking plate fixation for dorsally displaced distal radial fractures in the elderly: a randomized controlled trial. J Bone Joint Surg Am. 2019;101(11):961-9.

21. Sirnio K, Leppilahti J, Ohtonen P, Flinkkila T. Early palmar plate fixation of distal radius fractures may benefit patients aged 50 years or older: a randomized trial comparing 2 different treatment protocols. Acta Orthop. 2019;90(2):123-8.

22. Zengin EC, Ozcan C, Aslan C, Bulut T, Sener M. Cast immobilization versus volar locking plate fixation of $\mathrm{AO}$ type $\mathrm{C}$ distal radial fractures in patients aged 60 years and older. Acta Orthop Traumatol Turc. 2019;53(1):15-8.

23. Anzarut A, Johnson JA, Rowe BH, Lambert RG, Blitz S, Majumdar SR. Radiologic and patient-reported functional outcomes in an elderly cohort with conservatively treated distal radius fractures. J Hand Surg [Am]. 2004 29(6):1121-7.

24. Handoll HH, Madhok R. Surgical interventions for treating distal radial fractures in adults. The Cochrane database of systematic reviews. 2003;3: CD003209.

25. Xu GY, Qiu Y, Mao HJ. A network meta-analysis of outcomes of 7 surgical treatments for distal radius fractures. Am J Ther. 2016;23(6):e1320-e8.

26. Vannabouathong C, Hussain N, Guerra-Farfan E, Bhandari M. Interventions for distal radius factures: a network meta-analysis of randomized trials. J Am Acad Orthop Surg. 2019;27(13):e596-605.

27. Franceschi F, Franceschetti E, Paciotti M, Cancilleri F, Maffulli N, Denaro V. Volar locking plates versus K-wire/pin fixation for the treatment of distal radial fractures: a systematic review and quantitative synthesis. Br Med Bull. 2015;115(1):91-110.

28. Caruso G, Tonon F, Gildone A, Andreotti M, Altavilla R, Valentini A, et al. Below-elbow or above-elbow cast for conservative treatment of extraarticular distal radius fractures with dorsal displacement: a prospective randomized trial. J Orthop Surg Res. 2019;14(1):477.

29. Pedersen J, Mortensen SO, Rolfing JD, Thorninger R. A protocol for a singlecenter, single-blinded randomized-controlled trial investigating volar plating versus conservative treatment of unstable distal radius fractures in patients older than 65 years. BMC Musculoskelet Disord. 2019;20(1):309.
30. Selles CA, Mulders MAM, Colaris JW, van Heijl M, Cleffken BI, Schep NWL. Arthroscopic debridement does not enhance surgical treatment of intraarticular distal radius fractures: a randomized controlled trial. J Hand Surg Eur Vol 2019:1753193419866128.

31. Shrank WH, Patrick AR, Brookhart MA. Healthy user and related biases in observational studies of preventive interventions: a primer for physicians. J Gen Intern Med. 2011;26(5):546-50.

32. Smeraglia F, Del Buono A, Maffulli N. Wrist arthroscopy in the management of articular distal radius fractures. Br Med Bull. 2016:119(1):157-65.

\section{Publisher's Note}

Springer Nature remains neutral with regard to jurisdictional claims in published maps and institutional affiliations.
Ready to submit your research? Choose BMC and benefit from:

- fast, convenient online submission

- thorough peer review by experienced researchers in your field

- rapid publication on acceptance

- support for research data, including large and complex data types

- gold Open Access which fosters wider collaboration and increased citations

- maximum visibility for your research: over $100 \mathrm{M}$ website views per year

At BMC, research is always in progress.

Learn more biomedcentral.com/submissions 